\begin{abstract}
ZHIRNOV, OKSANA VLADIMIROVNA. Action spectra for UV- light induced RNA-RNA crosslinking in $16 \mathrm{~S}$ ribosomal RNA in the ribosome. (Under the direction of Dr. Paul L. Wollenzien).
\end{abstract}

UV- light induced crosslinking has been used to study RNA structures since the 1970s. The idea behind the method is that if there is an interaction between two nucleotides in the RNA tertiary structure, either as a part of the same strand or as a part of intermolecular interaction, they sometime will form covalent bond or "crosslink" with each other upon exposure to the UV light. Importantly, these interactions seem to be specific, limited in number and the crosslinking efficiencies are sufficient to allow their use in monitoring conformational changes of macromolecules. The occurrence of crosslinks within macromolecules depends on a combination of factors, including the inherent photoreactivity of the nucleotides that are joined, the correct distance and geometrical arrangement of the nucleotides, the molecular dynamics at the site of the crosslink and the wavelength of UV light that is used for irradiation.

In this work, action spectra for eight out of fifteen 16S rRNA crosslinks were determined. For six of the crosslinks the action spectra correspond to the absorption spectra of at least one of the participating nucleotides. For two of them: C967 x C1400 and C1402 x C1501 the absorption maximum differs from the spectra of cytidine in aqua solution. The spectra for the $\mathrm{C} 1402 \mathrm{x}$ C1501 crosslink may be shifted because $\mathrm{C} 1402$ is posttranscriptionally modified to $\mathrm{m}^{4} \mathrm{Cm}$. This difference can also result from the influence of molecular environment at the absorption of nucleotides, participating in those crosslinks formation. 


\section{ACTION SPECTRA FOR UV-LIGHT INDUCED RNA-RNA CROSSLINKING IN 16S RIBOSOMAL RNA IN THE RIBOSOME}

by

\section{OKSANA VLADIMIROVNA ZHIRNOV}

A thesis submitted to the Graduate Faculty of

North Carolina State University

In partial fulfillment of the requirements for the Degree of

Master of Science

BIOCHEMISTRY

Raleigh

2002

APPROVED BY:
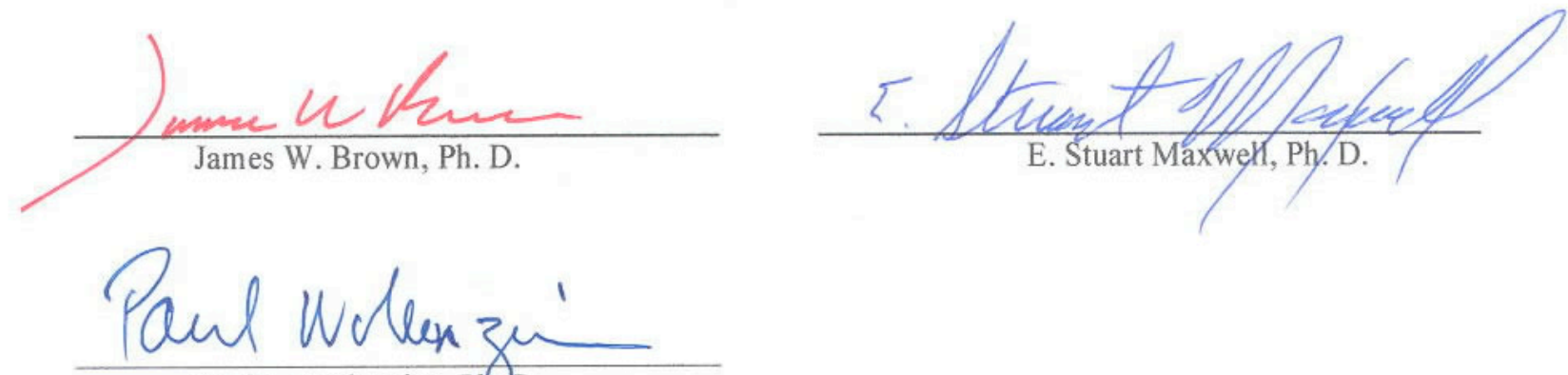

Paul L. Wolenzien, Ph.D.

Chair of Advisory Committee 


\section{DEDICATION}

This work is dedicated to my husband Victor Zhirnov. He had always encouraged me in any of my undertakings and attempts. 


\section{PERSONAL BIOGRAPHY}

Oksana V. Zhirnov is a doughter of Vladimir and Ludmila Balnov. Oksana was born on October 26, 1969 in Moscow, Russia. She attended secondary education at High School \#199 in Moscow, Russia. She received a Masters of Science degree from Moscow Institute of Fine Chemical Technology in the field of Biotechnology in 1992. After moving with her family to United States, Oksana entered the graduate program in Biochemistry at the North Carolina State University where she joined the lab of Dr. Paul Wollenzien in 2000. Upon completion of graduate

school my career goal is to work in research and development in the pharmaceutical or biotechnology industry. 


\section{ACKNOWLEDGMENTS}

I thank Professors James W. Brown and E. Stuart Maxwell for serving as committee members for their valuable time.

I would like to thank Dr. Stanislav Kirillov, Dr. Tatjana Shapkina, Dr. Dalia Juzumiene, Dr. Barbara Imoiolczyk, Kavita Arya, Wayne Huggins who are my co-workers and my friends for providing scientific guidance and support when things went not as well as they could.

I would like to thank Professor Paul Wollenzien for providing a good training in the lab. 


\section{TABLE OF CONTENTS}

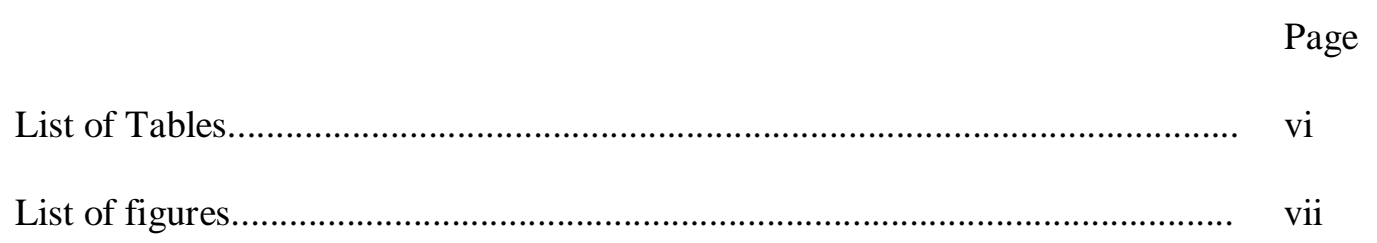

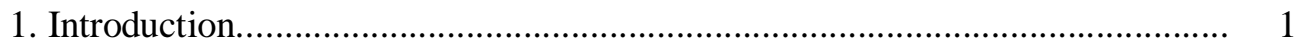

2. Materials and Methods.................................................................................. 9

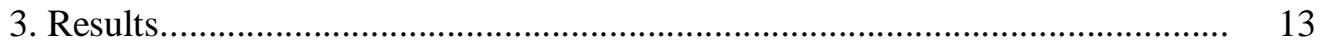

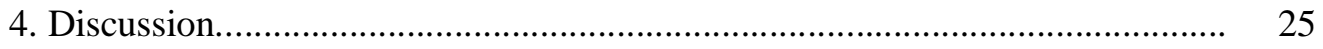

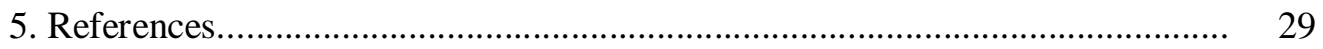




\section{LIST OF TABLES}

$\underline{\text { Results }}$

$\underline{\text { Page }}$

1. Determination of a factor $\mathrm{f}$ for further normalization of a dose of irradiance absorbed by each $30 \mathrm{~S}$ sample..

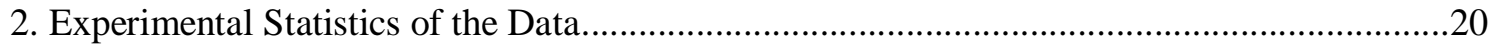

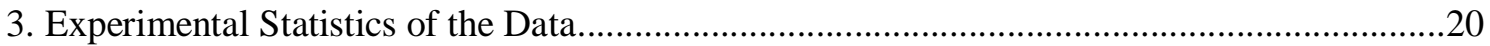




\section{LIST OF FIGURES}

$\underline{\text { Introduction }} \quad \underline{\text { Page }}$

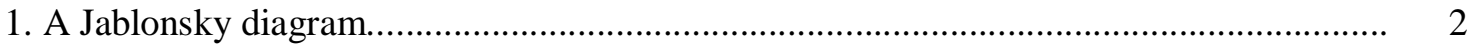

2. Absorption spectra of canonical nucleosides in far ultraviolet.......................................... 3

3. Secondary structure of $16 \mathrm{~S}$ rRNA with cross-links identified in $30 \mathrm{~S}$ and $70 \mathrm{~S}$ ribosomes.

Materials and Methods

4. Crosslinking dependence on light intensity determined by sizes of slits used in the monochromator.

$\underline{\text { Results }}$

5. Pattern of UV-induced crosslinking in the $30 \mathrm{~S}$ subunit.

6. Action spectrum for UV-light induced crosslinks in 16S rRNA:

6.1.

6.2

6.3

6.4 


\section{INTRODUCTION}

Photochemical reactions, involving condensation (crosslinking) of nucleotides and bases, have been investigated since the early work of Sinsheimer and Hasting in 1949, who studied the products of uracil after UV light irradiation in liquid and frozen solutions (1). The far UVinduced photodimers have been most extensively characterized for products containing pyrimidine nucleosides. The chemical structure of pyrimidine dimers include dimers joined by cyclobutane bridges involving the C5 - C6 of each base or involving a single covalent bond between $\mathrm{C} 6$ to $\mathrm{C} 4$ of the partner base (2). These dimers are thought to occur through the triplet excited state due to the extreme short half life of the singlet state ( $1 / 2=0.4-1 \mu$ s and 10 ps for triplet and singlet states, respectively). Pyrimidine dimers in the case of bases, nucleosides and nucleotides are formed by reaction of one pyrimidine molecule in T1 with another one in S0 (2). Figure 1 shows a standard Jablonski diagram depicting possible radiative transitions that occur between different energy levels of an electronically excited molecule (3). Absorption of a photon results in the excitation of a molecule from the ground state $(\mathrm{S} 0)$ to the excited singlet state $(\mathrm{S} 1)$, which may then radiate the absorbed energy, or transfer the energy by a non-radiative intersystem crossing event to the triplet state (T1) (3). Energy transfer between excited nucleosides also occurs. The consequence of this is the transfer of energy into the lowest lying triplet states. In DNA energy transferred occurs from purines to pyrimidines.

For nucleotides in aqueous solution the photoreactivity of pyrimidines is about 10 fold greater than for purines (4). The absorption spectra for four canonical nucleosides (Figure 2) have the following maxima: A - $260 \mathrm{~nm} ; \mathrm{G}-252 \mathrm{~nm}, 277 \mathrm{~nm}$ (shoulder); C - $271 \mathrm{~nm}$ and U - $261 \mathrm{~nm}$ (5). Photodimers formed via cyclobutane bridge absorb light at the shorter wavelengths in comparison with mononucleosides, so when a pyrimidine is converted to a dimer, the 5,6-bond is saturated and the absorption is lost.

The pyrimidine dimers are photoreversible (2). When a deoxygenated aqua solution of pyrimidine is irradiated near the wavelength of its maximum absorption $(\lambda \max )$, 


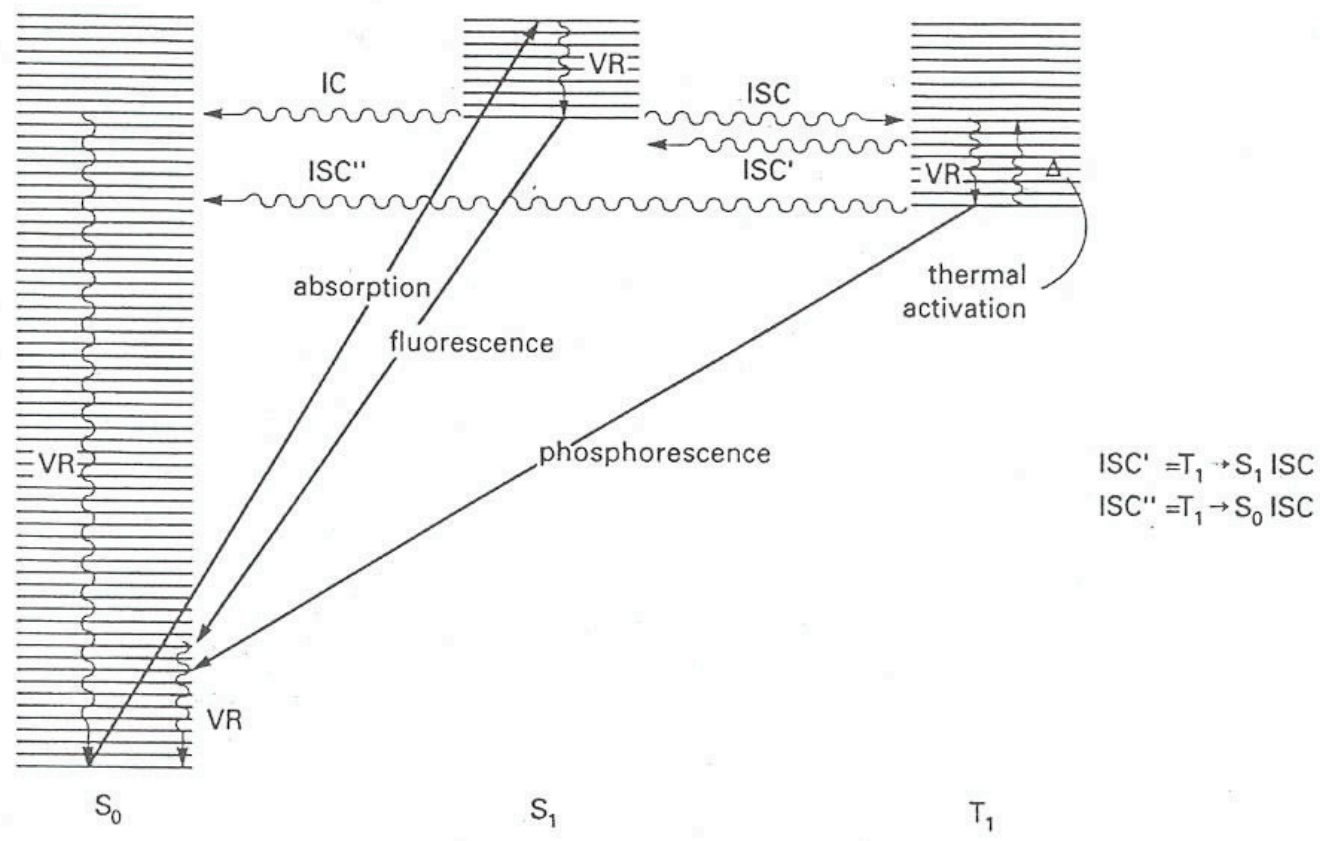

Figure 1. A Jablonsky Diagram. Transitions that involve electromagnetic radiation (both absorption and emission) are indicated as straight arrows, and non-radiative transitions are shown as wiggly arrows. Conversions between different spin multiplicity states are indicated as IC (internal conversion between same state atoms). Vibrational relaxation (VR) is indicated in each state (3). 


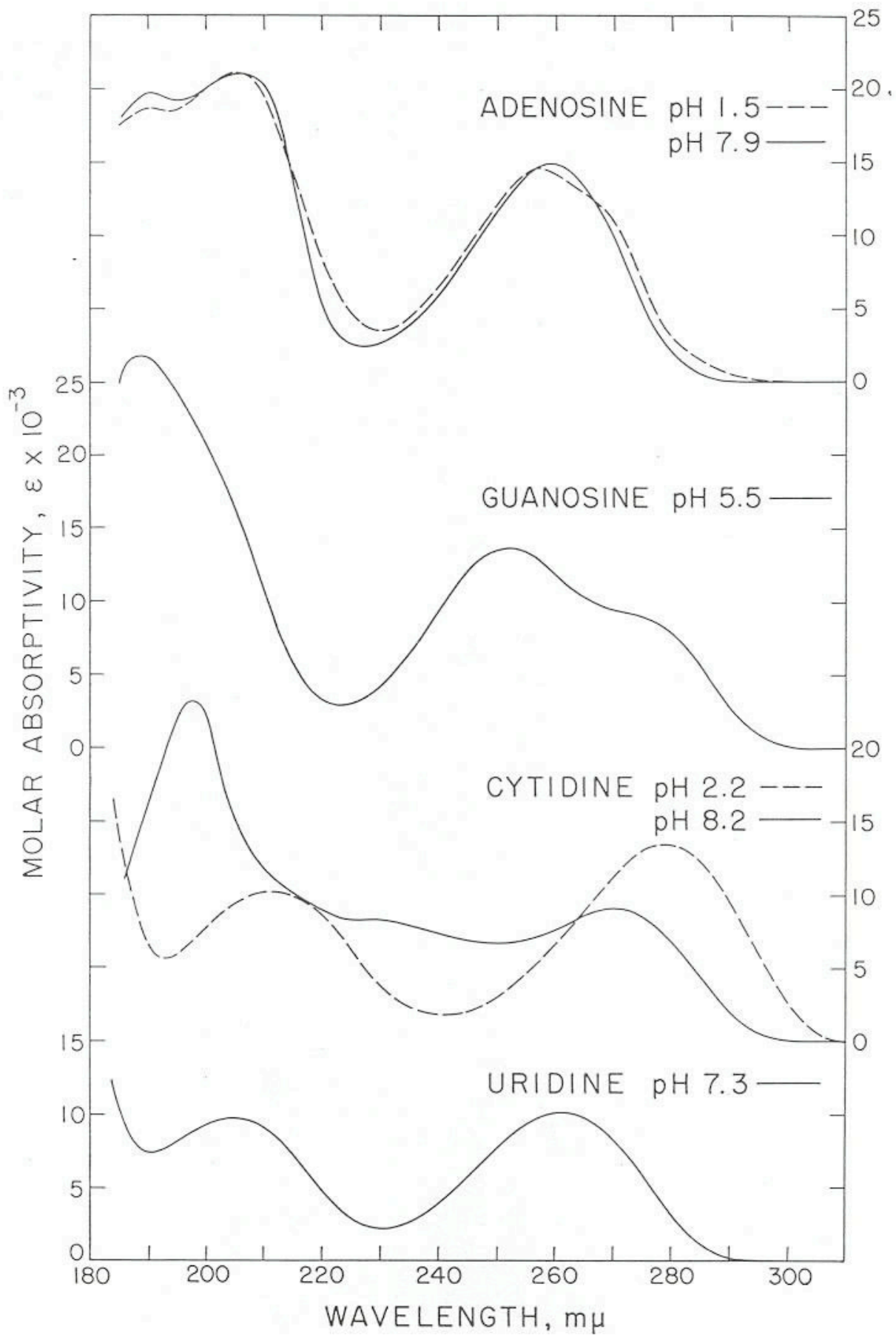

Figure 2. Absorption spectra of canonical nucleosides in far ultraviolet (5). 
monomers are converted to dimers. If the solution is then irradiated at a shorter wavelength at which the dimer absorbs more strongly, the optical density increases at the $\lambda$ max of the original monomer. This increase in optical density is due to the photoreversal of dimers to monomers. Orotic acid, uracil, thymine and cytosine photodimers are converted to monomers upon irradiation at $\lambda=235$ - $240 \mathrm{~nm}$ (6). These reactions are represented by Equation (1).

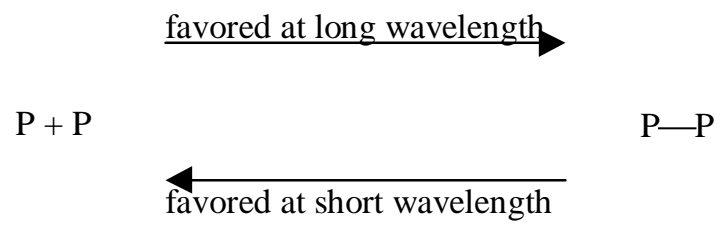

Orotic acid when irradiated in aqueous solution appears to form dimers almost exclusively $(7,8)$. The quantum yield for the reversal of thymine-thymine dimers $\left(\Phi_{\mathrm{dim}}\right)$ vary between 0.6 and 0.9 (9). Such photodimers are not unique to pyrimidines. Purines also able to dimerize under exposure to UV within nucleic acids (10 - 14). However, in aqua solutions, photolysis of purines very often leads to their complete decomposition (15). For adenine, decomposition is faster under oxygen, but the breakdown of guanine is inhibited by oxygen as compared with reactions performed under nitrogen. Adenine is essentially destroyed completely after $24 \mathrm{hr}$ of irradiation under aerobic conditions, whereas under nitrogen. $90 \%$ remains. This suggests oxidative breakdown, with the amino group being the point of attack. Two major dimeric photoproducts of dApdA were identified by Kumar et al (16). The mechanism involves a common intermediate, where two bonds are formed between $\mathrm{N} 7$ and $\mathrm{C} 8$ positions of one adenine molecule and $\mathrm{C} 6$ and C5, respectively of the other.

The phenomena of DNA crosslink formation has been investigated in the context of DNA damage and repair. In 1978 the action spectra of UV-rays for chromatin aberrations determined in embryonic fibroblasts from BALB mice exposed to the UV-rays at 254, 265, 280 and $302 \mathrm{mn}$ was 
found to be closely similar to the absorption spectra of thymidine and to the spectrum of DNA crosslinks formation (17). Irradiation of the cells in G2 phase of cell cycle at $265 \mathrm{~nm}$ resulted in maximum number of chromosomes with nucleotide deletions and mismatched bases on newly synthesized DNA strands in the mitosis phase of second round of the cell division. This DNA damage was thought to happen due to long lived thymidine-thimidine intermolecular crosslinks formed in G2 phase of previous cell cycle upon UV irradiation.

Dependence of thymine dimer formation on the wavelength of irradiation was investigated using well - defined monoclonal antibodies (18). This study demonstrated that the action spectra of thymine in DNA differ from that in aqua solutions and in dry films (19). The thymine dimer formation is most efficiently induced upon irradiation of DNA at $260 \mathrm{~nm}$, whereas in water solutions thymine has absorption maximum at $268 \mathrm{~nm}$.

Some cytosines are modified to uridines upon exposure to UV light and participate in uracil - thymine dimer formation (20). The quantum yield for cyclobutane-type 5,6-dipyrimidines thymine-thymine dimers (TT) in DNA irradiated at $254 \mathrm{~nm}$, including fraction of thymine that appears as UT-dimers, is $2.6 \times 10^{-3}(20)$. Values of quantum yield reported for the dimers resulted from DNA irradiation at $193 \mathrm{~nm}$ and $266 \mathrm{~nm}$ are $\Phi_{\operatorname{dim}}=1.7 \times 10^{-3}(21)$ and $\Phi_{\mathrm{dim}}=1.8 \times 10-3$ (22) respectively. From this $\Phi_{\text {dim }}$ can be expected to be independent of wavelength of irradiation in this region.

Crosslinking methods have been used to study RNA structures since the 1970s. Among these methods is the use of far UV light $(255-300 \mathrm{~nm})$ to produce RNA-RNA crosslinks by direct activation of the four canonical bases $(23,24)$. The idea behind the method is that if two nucleotides located at the long distance from each other in RNA primary structure are brought to close proximity in the RNA tertiary structure, the nucleotides may form a covalent bond or "crosslink" with each other upon exposure to the UV light. Importantly, these interactions seem to be specific, limited in number and the crosslinking efficiencies are good enough to allow their use 
in monitoring conformational changes of macromolecules. The occurrence of crosslinks within macromolecules depends on a combination of factors, including the inherent photoreactivity of the nucleotides that are joined, the correct distance and geometrical arrangement of the nucleotides, molecular dynamics at the site of the crosslink and the wavelength of UV light that is used for irradiation. A number of crosslinks, induced in E. coli $16 \mathrm{~S}$ ribosomal RNA by far-UV irradiation have been previously described (10 - 13) and crosslinks in similar positions were found in Bacillus subtilis and Thermus aquaticus (25). This similarity is caused by high degree of the RNA structure/sequence conservation in this three organisms. There is a high degree of secondary and tertiary structure identity in all of them. Additionally, Bacillus subtilis and T. aquaticus have $78 \%$ and $71 \% 16$ S rRNA sequence identity to E. coli respectively. Figure 3 shows the 16S rRNA crosslinks composition and location in E coli. The summary for the 16S rRNA crosslinks in these organisms is 24 pyrimidine - pyrimidine, seven pyrimidine - purine and five purine-purine crosslinks. These numbers suggest a strong preference for pyrimidine - pyrimidine crosslinks, however sufficient examples of purine-containing crosslinks exists to imply that the influencing factors of the orientation of the involved nucleotides, the degree of dynamic energy associated with those nucleotides and the surrounding electronic environment are important (26). This indicates that in the context of ribosome structure, purine residues may be arranged in interactions that change their electronic features, increase the efficiency of internucleotide reactions or decrease the rate of loss of excitation energy through energy transfer.

16S rRNA is 1542 nucleotide long complex molecule, folded in a way to participate in protein synthesis. The action absorbance spectra of nucleotides engaged in crosslinks formation may vary from those in aqua solutions due to molecular environment around crosslinks sites. The absorbance spectra may depend not only on base stacking interactions at the crosslink site, but also on positioning of polar and aromatic groups of surrounding nucleotides. The goal of this work is to determine the wavelength dependence of the crosslinks frequency for each of the 
crosslinks that occur in $E$.coli $16 \mathrm{~S}$ rRNA in the small ribosomal subunit. This allows evaluation of influence of intermolecular environment on individual crosslink formation. 


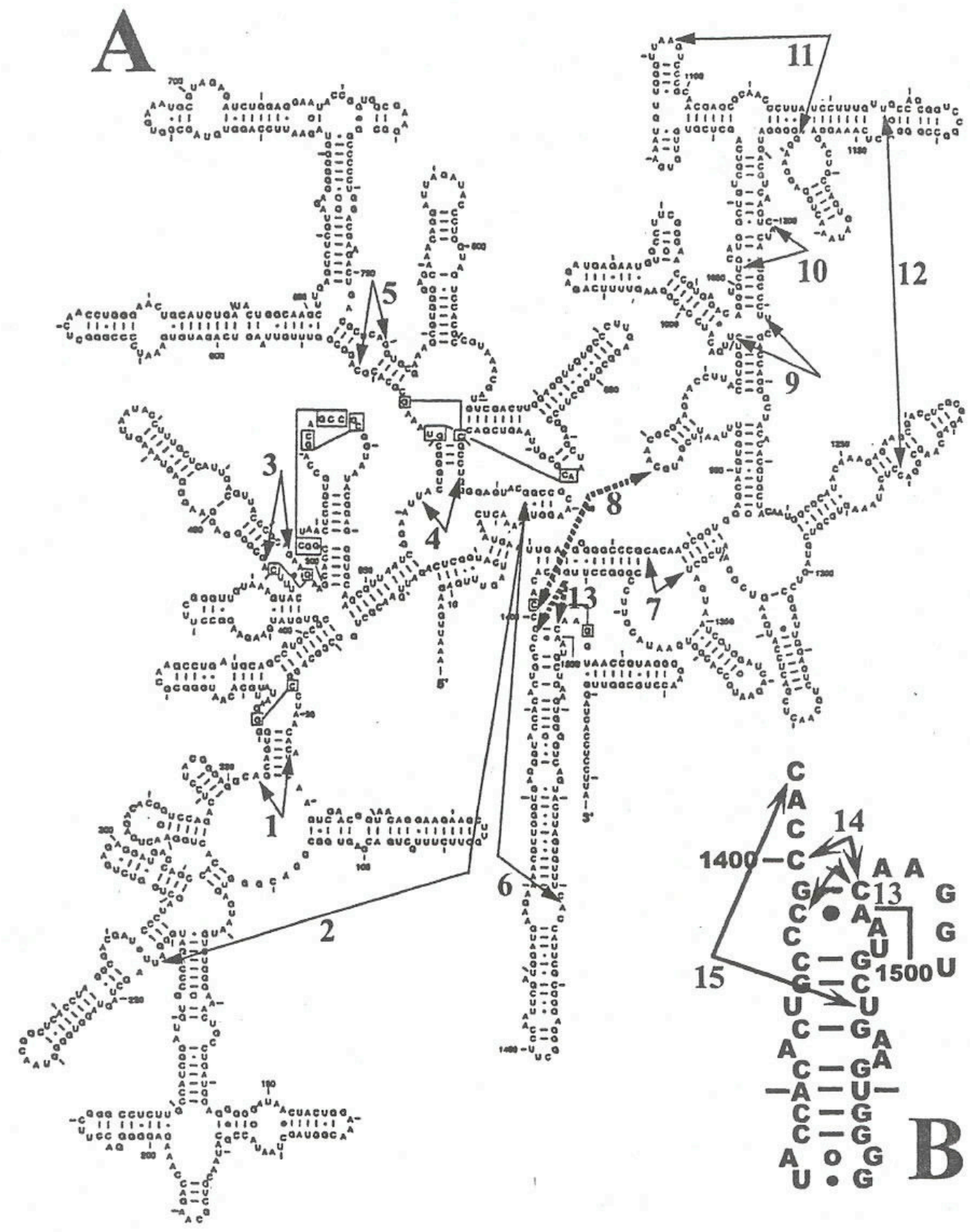

Figure 3. Secondary structure of $16 \mathrm{~S}$ rRNA with cross-links identified in $30 \mathrm{~S}$ and $70 \mathrm{~S}$ ribosomes. (A) Fifteen cross-links identified in 16S rRNA in 30S subunits. Numbering is as follows: 1 (C54 $\times$ A353), 2 $(\mathrm{G} 894 \times \mathrm{U} 244), 3(\mathrm{~A} 441 \times \mathrm{G} 494), 4(\mathrm{C} 562 \times \mathrm{U} 884), 5(\mathrm{C} 582 \times \mathrm{G} 760), 6(\mathrm{G} 894 \times \mathrm{A} 1468), 7(\mathrm{C} 934 \times$ U1345), 8 (C967 × C1400), 9 (U991 × U1212), 10 (U1052 × C1200), 11(A1093 × C1182), 12 (U1126 × C1281), $13(\mathrm{C} 1402 \times \mathrm{C} 1501), 14(\mathrm{C} 1400 \times \mathrm{C} 1501), 15(\mathrm{C} 1397 \times$ U1495). Cross-link 14, determined in this study (panel B) is formed in $30 \mathrm{~S}$ subunits and $70 \mathrm{~S}$ ribosomes. (B) Enlargement of the decoding region in 16S rRNA (25). 


\section{MATERIALS AND METHODS}

Preparation of $30 \mathrm{~S}$ small ribosomal subunits. Ribosomes and $30 \mathrm{~S}$ ribosomal subunits were isolated from E. coli cells grown to mid log phase and were prepared according to Makhno et al. (27). Frozen E.coli MRE 600 (1/2 log) cells were obtained from the Cell Culture Fermentation Facility, University of Alabama, Birmingham, AL. $40 \mathrm{~g}$ of frozen cells were resuspended in activation buffer $\mathrm{T}_{20} \mathrm{~A}_{200} \mathrm{M}_{20}\left(20 \mathrm{mM}\right.$ Tris- $\mathrm{HCl}, \mathrm{pH} 7.5,200 \mathrm{mM} \mathrm{NH} \mathrm{Cl}_{4}, 20 \mathrm{mM} \mathrm{MgCl} 2,4 \mathrm{mM} \beta$ mercaptoethanol) and cell membranes were fragmented by sonication. Cell debris was removed by centrifugation at $16,000 \mathrm{rev} / \mathrm{min}$ for $20 \mathrm{~min}$. and the supernatant was further centrifuged at $30,000 \mathrm{rev} / \mathrm{min}$ for $3 \mathrm{hrs}$ to obtain $70 \mathrm{~S}$ ribosomes. The resulting ribosomal pellet was dissolved in activation buffer. 30S small ribosomal subunits were obtain by centrifugation of $70 \mathrm{~S}$ ribosomes on exponential 7.5\%-30\% sucrose gradient prepared in $\mathrm{T}_{20} \mathrm{~A}_{200} \mathrm{M}_{3}$ buffer (20 mM Tris- $\mathrm{HCl}, \mathrm{pH}$ 7.5, $200 \mathrm{mM} \mathrm{NH}_{4} \mathrm{Cl}, 3 \mathrm{mM} \mathrm{MgCl}{ }_{2}, 4 \mathrm{mM} \beta$-mercaptoethanol) for $17 \mathrm{hrs}$ at 27,000 rev/min. Then $30 \mathrm{~S}$ subunit-containing portion of the gradient was identified by absorbance monitoring of the sucrose solution at $\lambda=280 \mathrm{~nm}$ on UA-6 UV/VIS detector and fractions containing $30 \mathrm{~S}$ were pooled, supplemented with $\mathrm{Mg}^{2+}$ to $20 \mathrm{mM}$ final concentration, and $30 \mathrm{~S}$ subunits were sedimentated by ultracentrifugation at 40,000 rev/min for $16 \mathrm{hrs}$. They were re-dissolved in activation buffer, activated $30^{\prime}$ at $37^{\circ} \mathrm{C}$ and frozen at $-85^{\circ} \mathrm{C}$ for storage.

Irradiation and purification of $30 S$ ribosomal subunits. All irradiations were done on $30 \mathrm{~S}$ ribosomal subunits. $30 \mathrm{~S}$ subunits were activated in the activation buffer at $37^{\circ} \mathrm{C}$ for $30 \mathrm{~min}$ and irradiated in the same buffer at $4^{\circ} \mathrm{C}$ at a concentration of $0.5 \mu \mathrm{g} / \mu \mathrm{L}$ in a quartz cuvette with continuous stirring and under a stream of nitrogen gas to remove oxygen. Irradiation was performed under nitrogen to avoid oxygen-mediated photoreactions (28). Under the irradiation conditions used, the crosslinking efficiency results in 0.15 crosslink per RNA molecule, so there 
should only be one crosslinked feature in one RNA molecule. UV wavelengths were selected from a $1000 \mathrm{~W}$ Xenon lamp (Model 6269 (Oriel Scientific Ltd.)) via a grating monochromator (Model 77250 (Oriel Scientific Ltd.)). Control samples were irradiated by broad wavelength far UV-light $(<300 \mathrm{~nm})$, produced in a transilluminator (Fotodyne, Inc.). After irradiation, 30S subunits were purified on $10 \%-30 \%$ sucrose gradient to remove residual $50 \mathrm{~S}$ subunits. For this purpose irradiated samples were applied to sucrose gradients in $\mathrm{T}_{20} \mathrm{~A}_{100} \mathrm{M}_{0.5}$ buffer ( $20 \mathrm{mM}$ Tris$\mathrm{HCl}, \mathrm{pH} 7.5,100 \mathrm{mM} \mathrm{NH}{ }_{4} \mathrm{Cl}, 0.5 \mathrm{mM} \mathrm{MgCl} 2,4 \mathrm{mM} \beta$-mercaptoethanol) and centrifuged at $25,000 \mathrm{rev} / \mathrm{min}$ for $16 \mathrm{hrs}$. Fractions containing $30 \mathrm{~S}$ were pooled together and $30 \mathrm{~S}$ were precipitated from the sucrose solution with 0.7 volume of ethanol. Finally, 30S subunits were sedimentated by centrifugation at $8,000 \mathrm{rev} / \mathrm{min}$ for $30 \mathrm{~min}$. and the pellets were further used for 16S rRNA isolation.

Isolation of $16 S$ rRNA from $30 S$ ribosomal subunits. $30 \mathrm{~S}$ subunits were extensively deproteinated before further analysis. The $30 \mathrm{~S}$ mixture was incubated with $1.0 \mu \mathrm{g} / \mu \mathrm{l}$ Proteinase $\mathrm{K}$ and $1.0 \% \mathrm{SDS} / 0.02 \mathrm{M}$ EDTA at $37^{\circ} \mathrm{C}$ for $30 \mathrm{~min}$. This was followed by phenol extraction to remove residual peptides (with back extraction of phenol phases with $\mathrm{H}_{2} \mathrm{O}$ ), an ether extraction to remove phenol from the combined aqueous phases and ethanol precipitation of the RNA were accomplished by the addition of 0.2 volume of $5.5 \mathrm{M} \mathrm{NH}_{4} \mathrm{OAc}, \mathrm{pH} 5$ and two volumes of ethanol (29). The RNA precipitate was washed with $70 \%$ ethanol, dried briefly in a speed vac and redissolved in $10 \mu \mathrm{l} \mathrm{H}_{2} \mathrm{O}$.

Preparation of $\left[5^{3}-{ }^{32} \mathrm{P}\right] p C \mathrm{P}$ and RNA labeling. 16S rRNA was labeled with radioactive isotope to allow analysis of crosslinks using gel electrophoresis and phosphoimager. In this experiments, the $3^{\prime}$ end of the RNA was labeled with $\left[5^{\prime}-{ }^{32} \mathrm{P}\right] \mathrm{pCp}$, because $\mathrm{pCp}$ is the best available donor for the $3^{\prime}$ terminal labeling reaction. The reaction containing $0.2 \mu \mathrm{M}$ of $\left[\gamma^{-32} \mathrm{P}\right] \mathrm{ATP}$ (500- 
2000i/mmole), $1 \mathrm{mM}$ of 3' CMP, $5 \mathrm{mM}$ of $\mathrm{MgCl} 2,3 \mathrm{mM}$ dithiothreitol (DTT), $50 \mu \mathrm{g} / \mathrm{ml}$ serum albumin (BSA), and 60 units $/ \mathrm{ml}$ of $\mathrm{T} 4$ polynucleotide kinase was incubated at $37^{\circ}$ for $90 \mathrm{~min}$. and then boiled for $15 \mathrm{~min}$. to eliminate the enzyme (30). The resulting $\left[5{ }^{3}-{ }^{32} \mathrm{P}\right] \mathrm{pCp}$ was further used for 16S RNA 3' labeling. The RNA labeling reactions were done with 20 pmol of $16 \mathrm{~S}$ rRNA, $0.2 \mu \mathrm{M}\left[5^{3}{ }^{32} \mathrm{P}\right] \mathrm{pCp}$ and 10 units T4 RNA ligase, in $50 \mu$ ligation buffer (50 mM Tris$\mathrm{HCl}, \mathrm{pH} 7.8,20 \mathrm{mM} \mathrm{Mg}(\mathrm{OAc})_{2}, 3.3 \mathrm{mM}$ DTT, $25 \mu \mathrm{M}$ ATP, $20 \mu \mathrm{g} / \mu \mathrm{l}$ BSA, 10\% DMSO) overnight at $4{ }^{\circ} \mathrm{C}(31,32)$. The RNA was phenol and ether extracted and unincorporated $\left[{ }^{32} \mathrm{P}\right] \mathrm{pCp}$ was removed by two ethanol precipitations using $2.5 \mathrm{M} \mathrm{NH}_{4} \mathrm{OAc}$ and $2.5 \mathrm{vol} \mathrm{EtOH}$ for precipitation.

Gel electrophoresis. 16S RNA crosslinked molecules were separated on denaturing polyacrylamide gels. The general principle of the separation is that RNA containing larger loops move slower than the molecules with smaller loops. Loops smaller than 50 nucleotides are not separated from the parent RNA and loops larger than about 500 nucleotides are not separated from one another (13).

For better resolution $1 \mu \mathrm{g}$ of RNA in $70 \%$ formamide (with $0.02 \% \mathrm{w} / \mathrm{v}$ bromphenol blue and $0.02 \%$ w/v xylene cylanol FF dyes) was loaded on $1-\mathrm{cm}$ wide well of a $0.35 \mathrm{~mm}$ thick by 40 cm long polyacrylamide gel which is $3.6 \%$ acrylamide: bisacrylamide (70:1), $8.3 \mathrm{M}$ urea in BTBE buffer (30 mM Bis-tris, $30 \mathrm{mM}$ boric acid, $2.5 \mathrm{mM}$ EDTA, pH 6.8). The gel, thermostated at $45^{\circ} \mathrm{C}$, was run for 18 hours at 6 watts constant power. The buffer in the gel reservoirs was slowly recirculated to prevent polarization and to compensate the top reservoir because of leaking during the overnight run. After electrophoresis, the gel was transferred to paper, dried and the pattern and frequency of crosslinked species were determined with a phosphoimager. 
Calculation of the crosslinks intensities. Crosslink frequencies were calculated from band intensities using Image Quant software, normalizing the RNA loading accordingly with uncrosslinked RNA (parent band) of a control sample. The light flux from the Xenon lamp decreases somewhat at lower wavelength, so a second correction was made for this. Differences in the dose of the UV light absorbed by each sample were calculated by multiplying of individual band intensities by a factor, calculated with the formula (1).

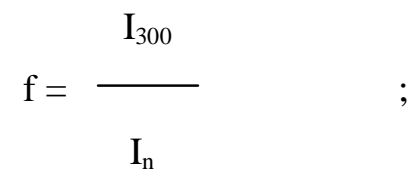

Where $I_{n}$ is the lamp irradiance at any wavelength used, obtained from the manufacturer's $1000 \mathrm{~W}$ Xenon lamp irradiance graph;

$\mathrm{I}_{300}$ is the lamp irradiance at $\lambda=300 \mathrm{~nm}$.

\section{Calculation of the mean values of relative frequencies of the crosslinks and standard deviation}

of the data. The relative frequencies of the crosslinks were calculated as a ratio of individual band intensities to the intensity of a parent band of a control sample. Mean values of relative frequencies of the crosslinks were calculated from two independent experiments accordingly with a formula (2):

$$
\overline{\mathrm{x}}=\left(\mathrm{x}_{1}+\mathrm{x}_{2}\right) / 2 \quad ;
$$

Where $\mathrm{x}_{1}$ is a relative frequency the crosslink obtained from experiment \# $1 ; \mathrm{x}_{2}$ is a relative frequency of the crosslink obtained from experiment \# 2; and $\overline{\mathrm{x}}$ is a mean value.

The standard deviation of the data was calculated according with a formula (3):

$$
\sigma=\sqrt{\frac{(x-\bar{x})^{2}}{n}} ;
$$

Where $\sigma$ is a standard deviation; $\mathrm{x}=\mathrm{x}_{1}$ or $\mathrm{x}_{2}$ and $\mathrm{n}=2$ 


\section{RESULTS}

Ribonucleic acids solutions absorb light in the wavelength range of $\lambda=220--300 \mathrm{~nm}$, with the absorbance maximum at $257 \mathrm{~nm}$. However, wavelengths of maximum absorbtion $(\lambda$ max) vary for different kinds of nucleotides, so the formation of different photoactivated nucleotide - nucleotide crosslinks within an RNA molecule might show different profiles of wavelength dependence. To investigate this $30 \mathrm{~S}$ ribosomal subunits were irradiated in the wavelength range of $\lambda=250--300 \mathrm{~nm}$ with irradiation doses that produce much less than one long range UV crosslink per molecule. A control sample was irradiated by broad far-UV light. 16S RNA was isolated and electrophoresed on denaturing polyacrylamide gel. This electrophoresis separates molecules on the basis of the crosslinks they contain and allows determination of crosslink frequency for individual crosslinks. Determination of the change in the crosslink frequency as a function of wavelength of irradiation allows evaluation of the influence of intermolecular environment on individual crosslink formation.

Optimization of experimental conditions. In this experiment, the optical system consisted of the 1000W Xenon lamp (light source), and grating monochromator, which was used for wavelength selection. Since radiant flux at the outer slit of the monochromator is tremendously smaller then radiant flux produced by the light source due to wavelength selection and dispersion, the experiment was designed to maximize light through the system to enable crosslinks formation.

$\phi=\mathrm{tGL} ;$ where

$\phi=$ is the radiant flux which reaches the sample;

$\mathrm{t}=$ transmittance $(\mathrm{t}$ includes reflection losses within the optical system and transmittances of its components); 
$\mathrm{G}=$ geometrical extent;

$\mathrm{L}=$ radiance of the light source.

To increase light through the system, the dimensions of inner and outer slits of the monochromator were changed from $1.56 \mathrm{~mm}$ x $12 \mathrm{~mm}$ with a half peak width of $10 \mathrm{~nm}$ to 3.16 $\mathrm{mm} \times 12 \mathrm{~mm}$ with a half peak width of $20 \mathrm{~nm}$. Additionally, to increase dose of irradiance absorbed by a sample, time of irradiation was increased from 20 min to 1 hour. Figure 4 demonstrates differences in crosslink intensities depending on the slit type used. When $30 \mathrm{~S}$ ribosomal subunits were irradiated at $\lambda=271 \mathrm{~nm}$ through $1.56 \mathrm{~mm} \times 12 \mathrm{~mm}$ slits with following 16S RNA isolation and its electrophoresis on polyacrylamide gel only some of the crosslinks are seen as faint bands on the gel (Figure 1, panel A, lane 2). Exchange of $1.56 \mathrm{~mm}$ x $12 \mathrm{~mm}$ slits with $3.16 \mathrm{~mm}$ x $12 \mathrm{~mm}$ slits resulted in frequencies of crosslinks formed under irradiation at 270 nm (Figure 1, panel B, lane 2) comparable with those of a control sample, irradiated at broad farUV light (Figure 1, panel B, lane 1). 
A

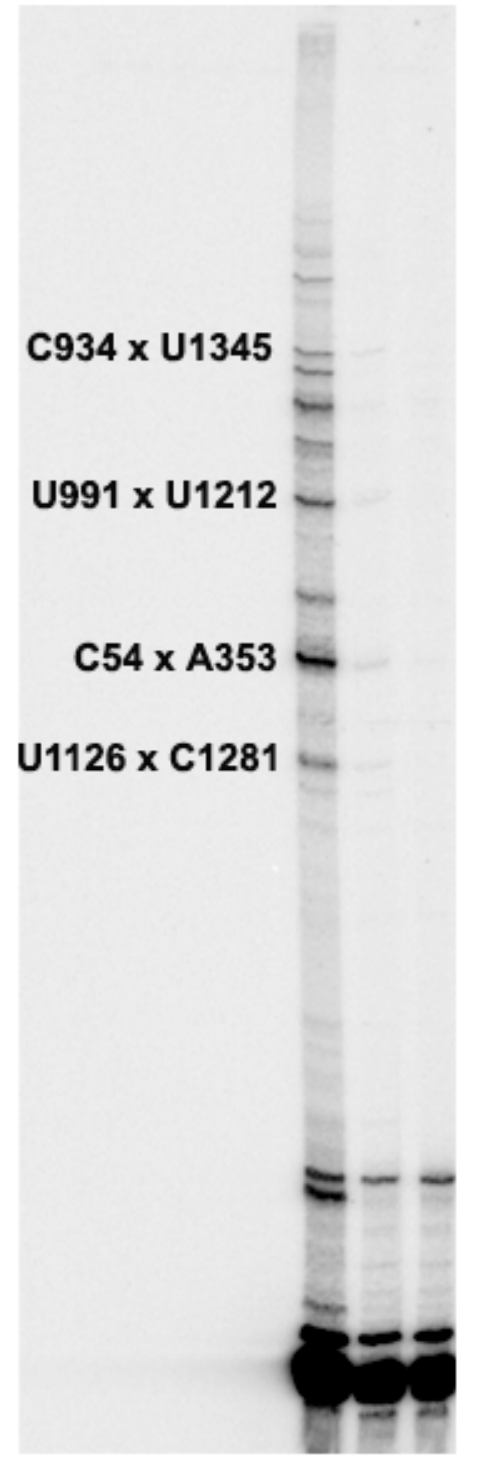

123
B

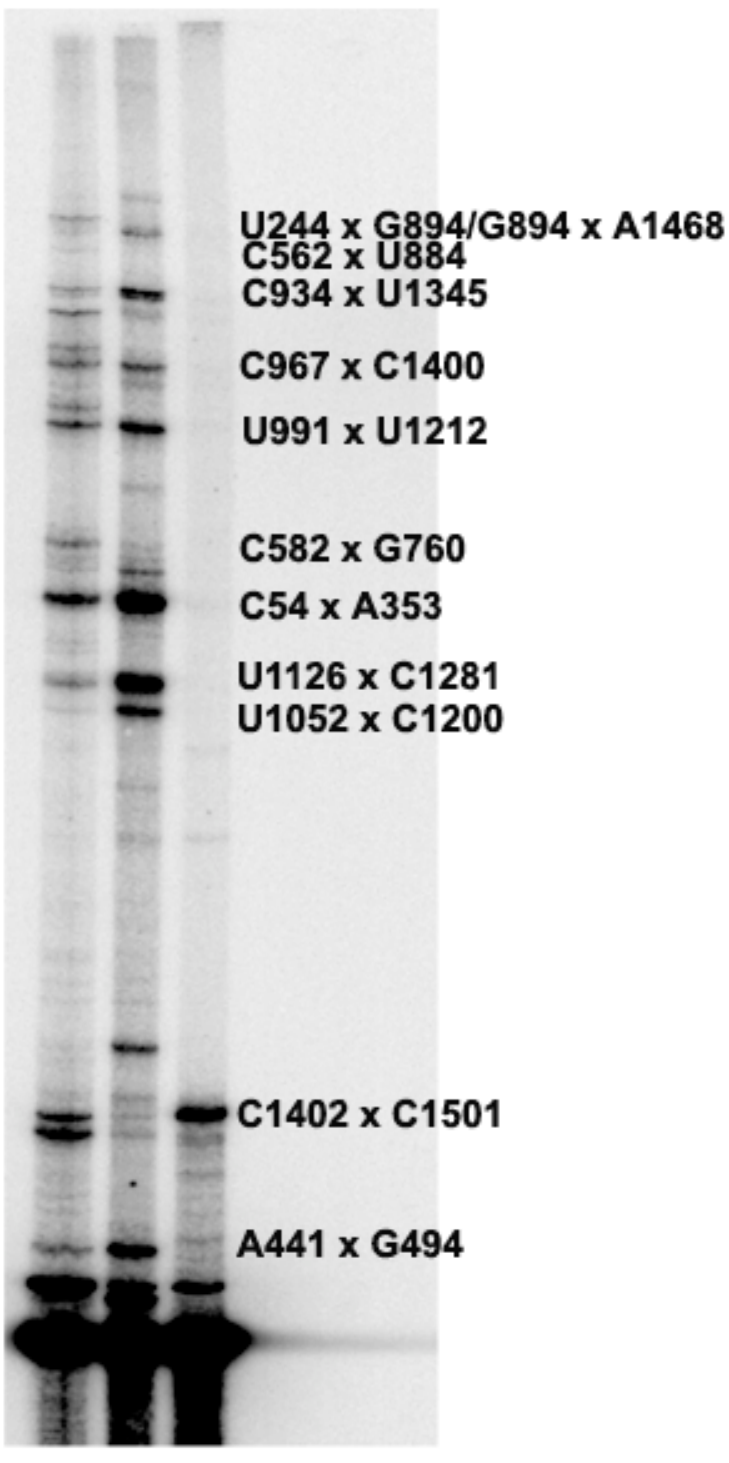

Figure 4. Crosslinking dependence on light intensity determined by sizes of slits used in the monochromator. All $30 \mathrm{~S}$ samples were irradiated with UV light of broad wavelength, $271 \mathrm{~nm}$ (max) or $305 \mathrm{~nm}$ (max). 16S rRNA was purified and then $3^{\prime}[32 \mathrm{P}]$-end labeled. The Figure shows the pattern of gel electrophoresis of the RNA samples on polyacrylamide gels. The identity of the nucleotides in the 16S rRNA (1542 ntd. total length) that are joined in prominent crosslinks are written in the right and left margins. In A, for lanes 2 and 3 the dimensions of the entrance and exit slits of the monochromator were $1.56 \mathrm{~mm} \times 12 \mathrm{~mm}$. In B, for lanes 2 and 3 the dimensions were $3.16 \mathrm{~mm} \times 12 \mathrm{~mm}$. In $A$ and $B$, the sample in lane 1 was irradiated at the broad far-UV light, in lane 2 - at the wavelength of $271 \mathrm{~nm}$, in lane 3 - at $305 \mathrm{~nm}$. 
Estimation of relative irradiance produced by the $1000 \mathrm{~W}$ Xenon lamp at different wavelengths. The study of the pattern and frequency of RNA crosslinks as a function of wavelength of irradiation requires estimation of light intensity produced by $1000 \mathrm{~W}$ Xenon lamp at different wavelengths of irradiation. Those values were calculated from manufacturer's $1000 \mathrm{~W}$ Xenon lamp irradiance graph for the wavelengths used for irradiation accordingly with a formula:

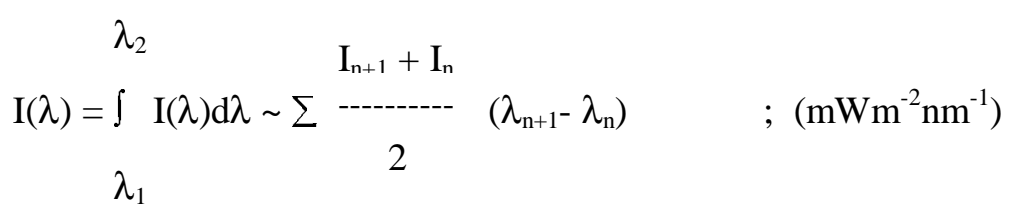

where $\lambda$ is a wavelength of irradiation, $\lambda_{2}>\lambda_{1}$; and $\mathrm{I}$ is a light intensity at the wavelength of irradiation; $I_{n+1}>I_{n}$

Table 1. Determination of a factor $f$ for normalization of a dose of irradiance absorbed by each $30 \mathrm{~S}$ subunit sample.

\begin{tabular}{|l|l|l|}
\hline$\lambda$, Wavelength of irradiation; $\mathrm{nm}$ & I, Light intensity; $\mathrm{mWm}^{-2} \mathrm{~nm}^{-1}$ & $\mathrm{f}$ \\
\hline 240 & 470 & 5.2 \\
\hline 250 & 960 & 2.55 \\
\hline 260 & 1350 & 1.8 \\
\hline 270 & 1600 & 1.53 \\
\hline 280 & 1800 & 1.36 \\
\hline 290 & 2075 & 1.18 \\
\hline 300 & 2450 & 1 \\
\hline
\end{tabular}

This calculations show that radiance produced by the light source does not change significantly in the range of wavelengths chosen for irradiation $(250-300 \mathrm{~nm})$. This fact allows 
us to normalize a dose of irradiance absorbed by each sample for estimation of the crosslinks intensity. It is difficult to accurately estimate the correction factor for $240 \mathrm{n}$ because of the very skip decrease in irradiance in the 250 - $230 \mathrm{~nm}$ wavelengths. Difference in the dose of the UV light absorbed by each sample was overcome by multiplying of individual band intensities by a factor f, calculated as explained in Materials and Methods section.

Monitoring of the crosslinks frequency at different wavelengths of irradiation. Two independent experiments were performed to monitor frequency of crosslinks at different wavelengths of irradiation. In each experiment individual band intensities were calculated as described in Materials and Methods section in order to construct a curve of the crosslinks absorbance versus wavelengths of irradiation.

Figure 5 shows dependence of crosslink formation on a wavelength of irradiation. Wavelengths 240 - 290 were chosen for irradiation because A, C, G and U absorb light significantly in this range. $300 \mathrm{~nm}$ was chosen as a reference (zero) point, because none of the canonical bases absorb at this wavelength in aqua solutions. Action absorption spectra is determined unambiguously for eight of $16 \mathrm{~S}$ rRNA crosslinks. Figures $6.1-6.4$ show the action absorption spectra for the crosslinks in 16S rRNA. The plot was constructed using data from two independent experiments. For this purpose, the relative frequencies of the crosslinks were calculated as described in the Materials and Methods section and plotted versus the wavelength of irradiation. The error bars on the plot represent a standard deviation, which was calculated as explained in Materials and Methods section. Crosslinks U1126 x C1281, U1052 x C1200, C967 x C1400, C934 x U1345, U991 x U1212 and A441 x G494 are most frequently formed when 30S subunits are irradiated at $260 \mathrm{~nm}$. Crosslink C1402 x 1501 is highly represented after irradiation of $30 \mathrm{~S}$ sample at $290 \mathrm{~nm}$, and C54 x A353 - at $270 \mathrm{~nm}$. 


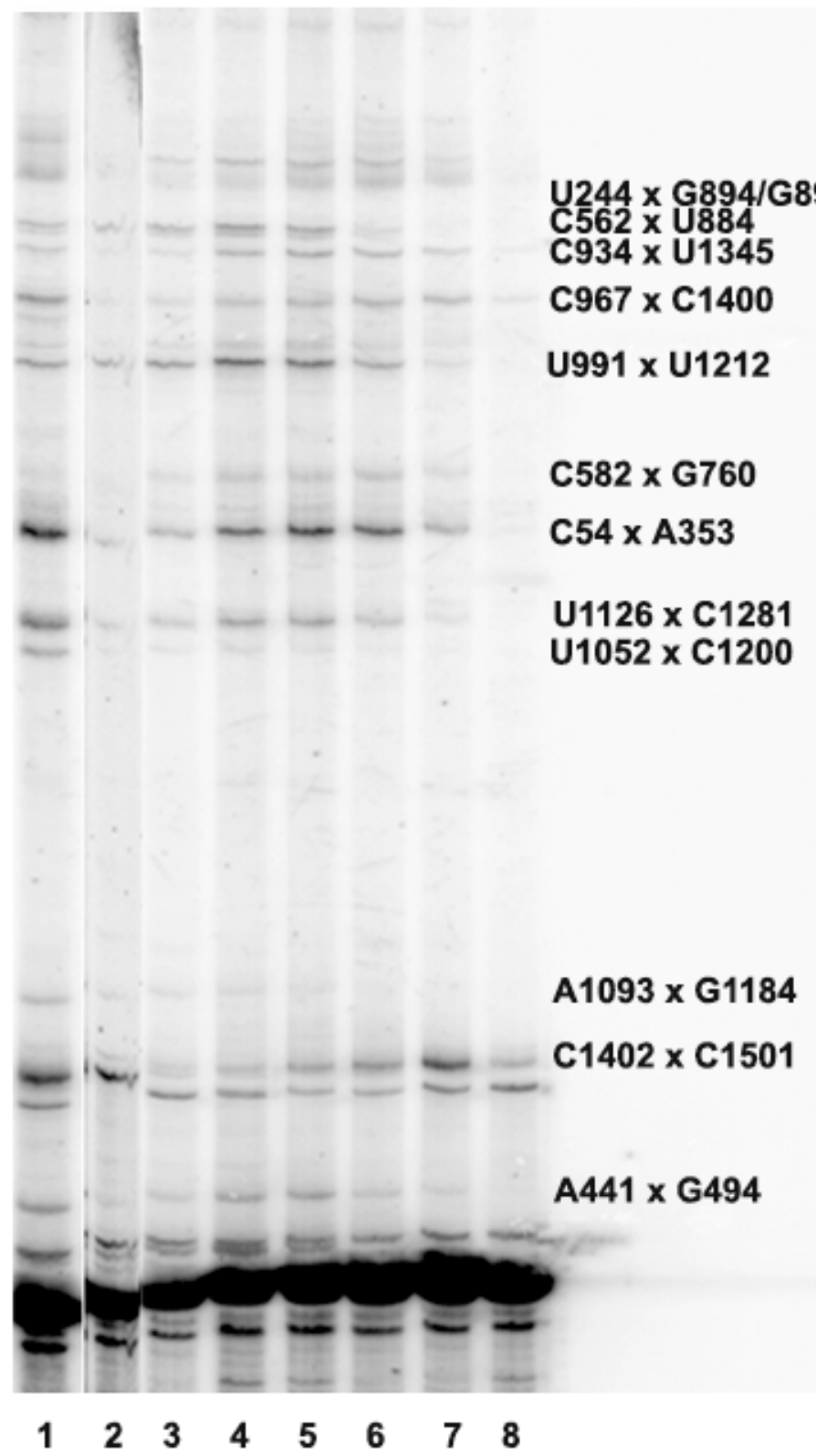

Figure 5. Pattern of UV-induced crosslinking in the $30 \mathrm{~S}$ subunit. All samples were irradiated with UV-light of different wavelength, purified for $16 \mathrm{~S}$ rRNA and were $3^{\prime}[32 \mathrm{P}]-$-end labeled. The Figure shows the pattern of gel electrophoresis of the RNA samples on polyacrylamide gel. In lane 1 the sample was irradiated at broad far-UV light; in lane 2 - at $240 \mathrm{~nm}$; in lane 3 - at $250 \mathrm{~nm}$; in lane 4 - at $260 \mathrm{~nm}$; in lane 5 - at $270 \mathrm{~nm}$; in lane 6 - at $280 \mathrm{~nm}$; in lane 7 - at $290 \mathrm{~nm}$; and in lane 8 - at $300 \mathrm{~nm}$. 
Unfortunately only eight out of twelve crosslinks separated by the denaturing polyacrylamide gels were analyzed. Crosslinks A1093 x G1184 and C582 x G760 appeared on the gels as faint, not well defined bands. Crosslinks U224 x G894/ G894 x A1468 and C562 x U884 were separated on one of the gels, but on the second gel appeared as a single band. Better conditions for increasing the gel resolution and for permanent separation of crosslinks U224 $\mathrm{x}$ G894/ G894 x A1468 and C562 x U884 can be determined via changing the ratio of acrylamide/bis-acrylamide, $\mathrm{pH}$ of the BTBE buffer and the percentage of acrylamide in the gel preparation. 
Table 2. Experimental Statistics of the Data

\begin{tabular}{|l|c|c|c|c|}
\hline \multicolumn{7}{|c|}{$\overline{\mathrm{x}} \pm \sigma$} \\
\hline $\begin{array}{l}\text { wavelength, } \\
\mathrm{nm}\end{array}$ & C54 x A353 & U991 x U1212 & C967 x C1400 & C934 x U1345 \\
\hline 250 & $0.012 \pm 0.004$ & $0.014 \pm 0.006$ & $0.005 \pm 0.002$ & $0.004 \pm 0.001$ \\
\hline 260 & $0.020 \pm 0.007$ & $0.016 \pm 0.009$ & $0.008 \pm 0.002$ & $0.005 \pm 0.002$ \\
\hline 270 & $0.030 \pm 0.005$ & $0.011 \pm 0.006$ & $0.005 \pm 0.002$ & $0.005 \pm 0.001$ \\
\hline 280 & $0.020 \pm 0.003$ & $0.005 \pm 0.001$ & $0.004 \pm 0.002$ & $0.003 \pm 0.0004$ \\
\hline 290 & $0.005 \pm 0.002$ & $0.0014 \pm 0.001$ & $0.003 \pm 0.002$ & $0.001 \pm 0.001$ \\
\hline 300 & $0.0008 \pm 0.00002$ & $0.0006 \pm 0.0001$ & $0.0009 \pm 0.0001$ & $0.0006 \pm 0.0001$ \\
\hline
\end{tabular}

Table 3. Experimental Statistics of the Data

\begin{tabular}{|l|l|l|l|l|}
\hline \multicolumn{7}{|c|}{$\overline{\mathrm{x} \pm \sigma}$} \\
\hline $\begin{array}{l}\text { wavelength, } \\
\mathrm{nm}\end{array}$ & \multicolumn{1}{|c|}{$\mathrm{A} 441 \times \mathrm{G} 494$} & \multicolumn{1}{c|}{$\mathrm{C} 1402 \times \mathrm{C} 1501$} & $\mathrm{U} 1052 \times \mathrm{C} 1200$ & $\mathrm{U} 1126 \times \mathrm{C} 1281$ \\
\hline 250 & $0.015 \pm 0.002$ & $0.014 \pm 0.003$ & $0.004 \pm 0.0002$ & $0.009 \pm 0.002$ \\
\hline 260 & $0.017 \pm 0.001$ & $0.012 \pm 0.0001$ & $0.005 \pm 0.001$ & $0.001 \pm 0.001$ \\
\hline 270 & $0.014 \pm 0.0002$ & $0.011 \pm 0.004$ & $0.004 \pm 0.002$ & $0.012 \pm 0.002$ \\
\hline 280 & $0.008 \pm 0.001$ & $0.016 \pm 0.003$ & $0.001 \pm 0.0002$ & $0.005 \pm 0.001$ \\
\hline 290 & $0.006 \pm 0.0001$ & $0.017 \pm 0.02$ & $0.0009 \pm 0.0001$ & $0.002 \pm 0.0001$ \\
\hline 300 & $0.003 \pm 0.0001$ & $0.004 \pm 0.004$ & $0.0005 \pm 0.0001$ & $0.0006 \pm 0.0002$ \\
\hline
\end{tabular}

Where $\overline{\mathrm{x}}$ - is a mean value of the relative frequency of the crosslink;

$\sigma-$ is a standard deviation 

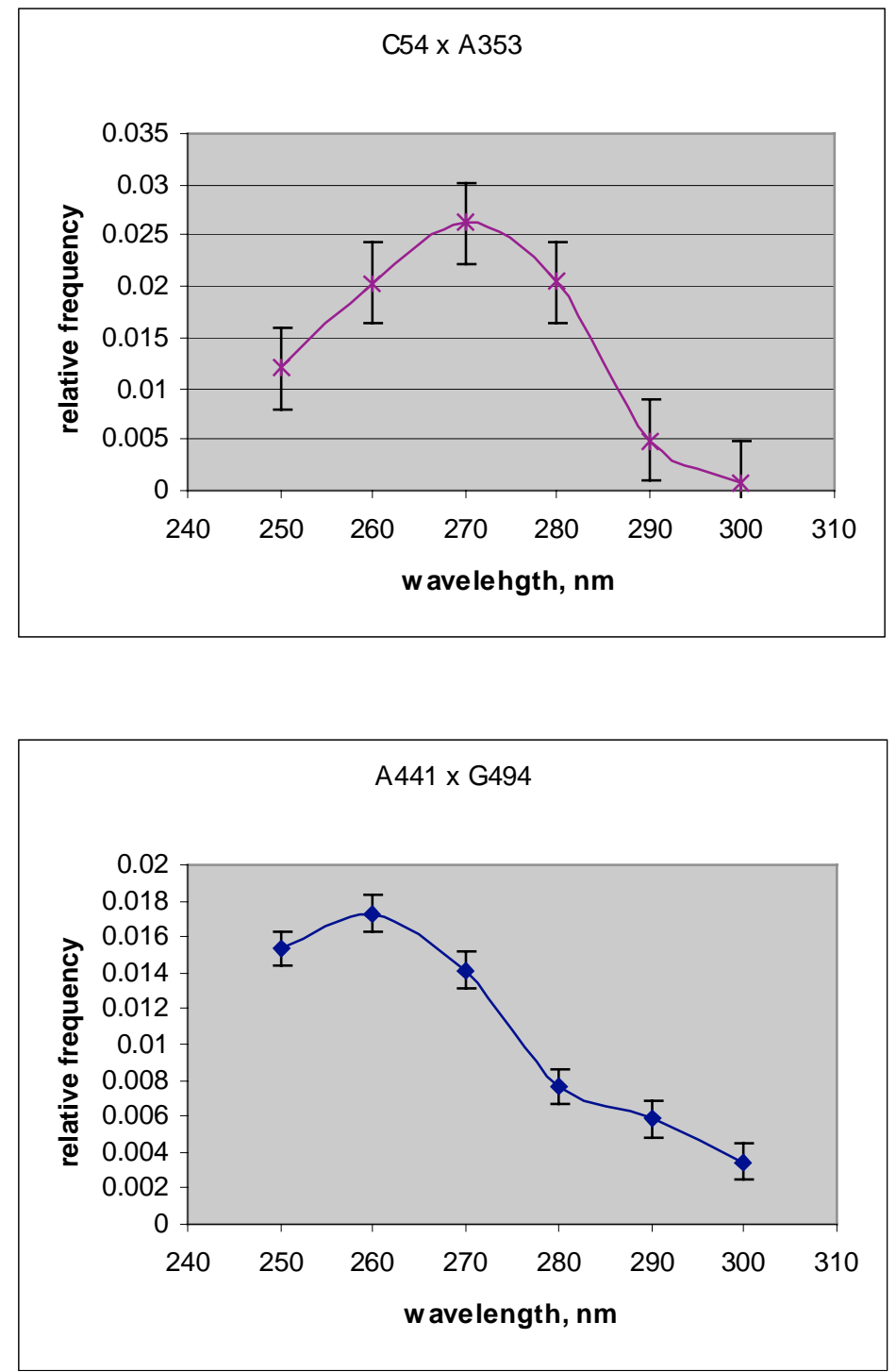

Figure 6.1. Action spectra for UV-light induced crosslinking in 16S rRNA. The plot is constructed using data from two independent experiments. The error bars on the plot represent an averaged standard deviation calculated from two different experiments. 

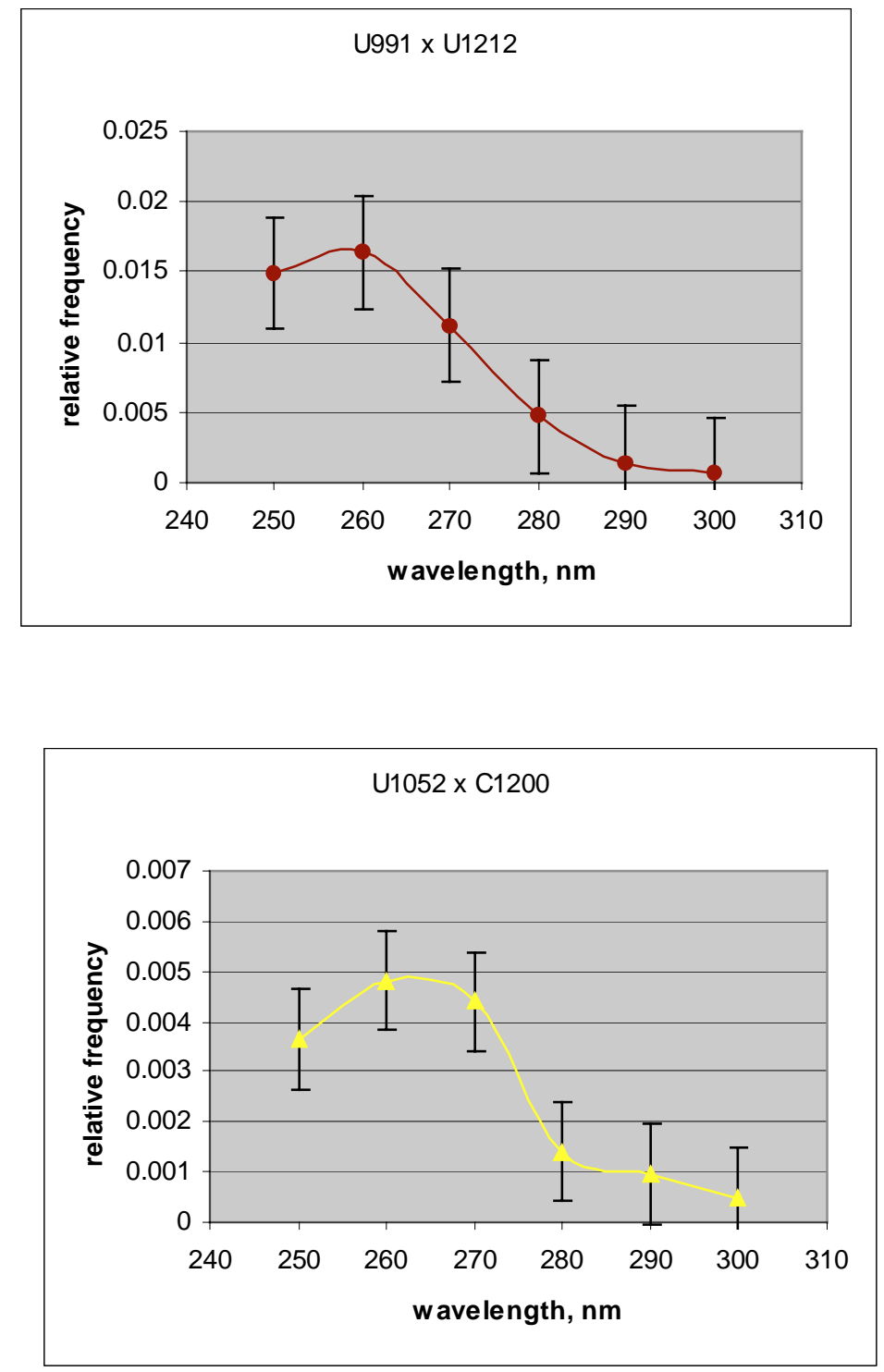

Figure 6.2. Action spectra for UV-light induced crosslinking in 16S rRNA. The plot is constructed using data from two independent experiments. The error bars on the plot represent an averaged standard deviation calculated from two different experiments. 

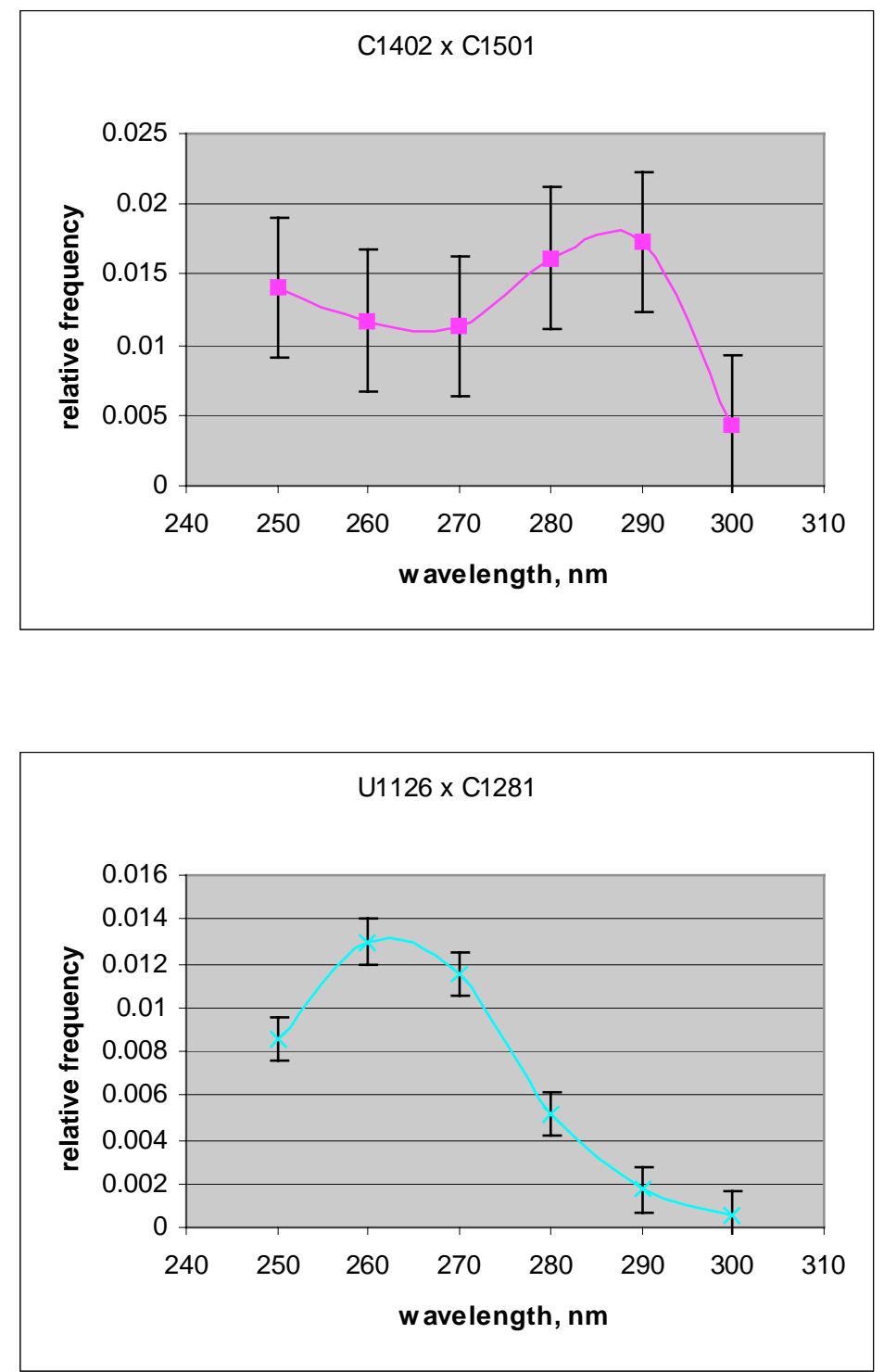

Figure 6.3. Action spectra for UV-light induced crosslinking in 16S rRNA. The plot is constructed using data from two independent experiments. The error bars on the plot represent an averaged standard deviation calculated from two different experiments. 

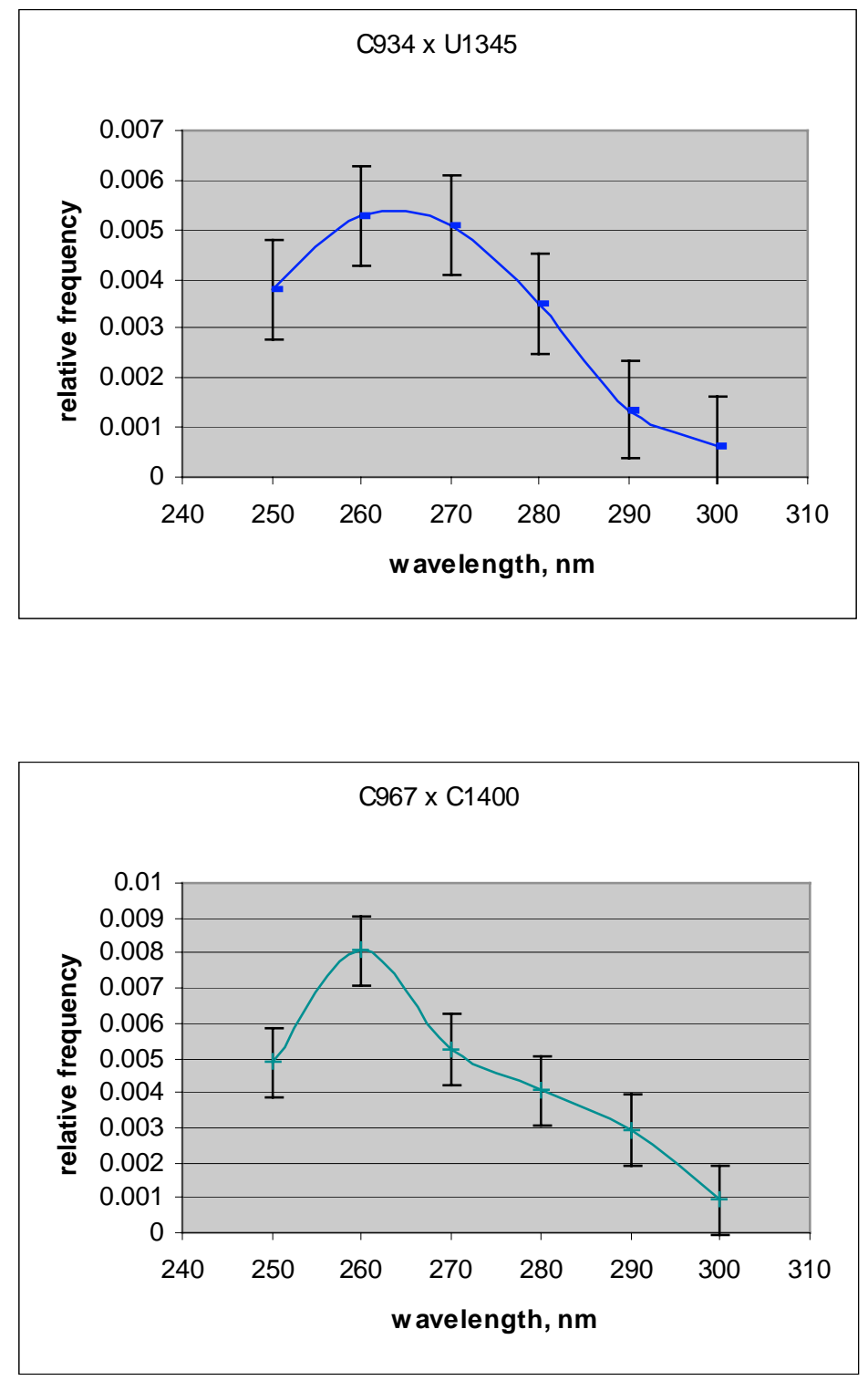

Figure 6.4. Action spectra for UV-light induced crosslinking in 16S rRNA. The plot is constructed using data from two independent experiments. The error bars on the plot represent an averaged standard deviation calculated from two different experiments. 


\section{DISCUSSION}

In this work the action absorption spectrum for eight out of fifteen 16S rRNA crosslinks was determined. It was possible to analyze these molecules because they had electrophoretic mobilities in the gel electrophoresis that allowed them to be well resolved and they were intense enough to give signals well above background. The results demonstrate that it is possible to determine 16S RNA crosslink formation dependence on wavelength of irradiation. Additionally, the action absorption spectra for some $16 \mathrm{~S}$ rRNA crosslinks resembles that for one of the nucleotides participating in the crosslink formation in water solution, but for some of them it differs in a way that suggests that molecular environment at the crosslink site is different from that in water solutions.

Crosslinks U1126 x C1281(Fig. 6.3), U1052 x C1200 (Fig. 6.2) and C934 x U1345 (Fig. 6.4) are most frequently formed upon irradiation of $30 \mathrm{~S}$ ribosomal subunits at $260 \mathrm{~nm}$. Uridine in water at $\mathrm{pH}=7.3$ has maximum absorption at 261 . Since the action spectra of those crosslinks within 16S rRNA resembles the absorption spectra of uridine in aqueous solutions we can conclude that uridine is more photoreactive then cytidine at those sites and in the majority of the cases excitation of uridine results in crosslink formation.

The action absorption spectrum of crosslink U991 x U1212 (Fig. 6.2) in 16S rRNA has a maximum at $260 \mathrm{~nm}$ which corresponds to the absorption maximum of uridine in aqueous solutions. Therefore, we conclude that the environment around these nucleotides is probably well hydrated.

The absorption spectrum of cytidine in aqueous solutions shows a strong peak $\sim$ at 271 nm. However, in 16S rRNA cytidines participating in C967 x C1400 crosslink formation have absorption maximum at $260 \mathrm{~nm}$ (Fig. 6.4). C967 is posttranscriptionally methylated at position C5. Previous data indicate that 5-hydroxymethylcytidine has a UV spectra similar to cytidine, except the $\lambda \max$ is shifted $4 \mathrm{~nm}$ to the red (271 and $275 \mathrm{~nm}$, respectively) (33), so the action spectra of crosslink C967 x C1400 does not resemble either that of intact cytidine or that of the 
cytidine modified at its fifth position of the base. This suggests that absorption of C967 and C1400 is influenced by molecular environment at this site. This is not a surprising observation, because this crosslink occurs in the decoding region of the 16S rRNA where secondary and tertiary structure elements are present. This implies that electronic environment at the decoding region differs significantly from that in solution.

Crosslink C1402 x C1501 is most enriched upon irradiation of $30 \mathrm{~S}$ samples at $290 \mathrm{~nm}$ (Fig. 6.3). C1402 is posttranscriptionally modified at position N4 with a methyl group. This methylation may be a reason for the shifting of the C1402 x C1501 absorption spectra to the red. However, such a big shift of the absorbance maximum can be also explained by the effect of electronic environment at that site. Unfortunately, I could not find any absorption spectra for $\mathrm{m}^{4} \mathrm{C}$, but from the spectra available for the other modified cytidines (33) it is reasonable to expect the absorption maximum for $\mathrm{m}^{4} \mathrm{C}$ to be shifted to the red, however, not at such a big extent as to $290 \mathrm{~nm}$.

The action absorption spectra of C54 x A353 resemble the absorption spectra of cytidine in water solutions (Fig. 6.1) because it has absorption maximum at $270 \mathrm{~nm}$. There is a better chance for a nucleotide to get exited at the wavelength of its maximum absorbance. Taking into account that one of the nucleotides should be in T1 excited state and the other - in S0 ground state for photodimer formation, we can assume that C54 x A353 in most cases is formed via the cytidine excitation.

The action spectra of crosslink A441 x G494 (Fig. 6.1) resembles the canonical absorption spectrum of adenosine in water, which shows maximum absorption at $260 \mathrm{~nm}$. However, the shape of the action spectra is slightly different then that of the absorption spectra of adenosine (A). There is nearly zero absorption by A at $280 \mathrm{~nm}$, but there is still significant photoreactivity for the A441 x G494 crosslink. This suggests that both the adenosine and guanosine may be active in initial photoreaction. 
There is a significant photoreversal reported for pyrimidine - pyrimidine photodimers in water solutions upon irradiation at $235-240 \mathrm{~nm}$. This could cause a potential difficulty in determination of absorption spectra of the crosslinks as a function of a wavelength of irradiation because the reversal to monomers could contribute to decrease in frequencies of individual crosslinks in undetectable way. However, 16S rRNA crosslink band intensities from 30S ribosomal subunits irradiated at $240 \mathrm{~nm}$ do not differ significantly from those at other wavelengths of irradiation tested, in particular at $250 \mathrm{~nm}$. This implies that there is no or little reversal of the crosslinks caused by irradiation at $240 \mathrm{~nm}$.

$16 \mathrm{~S}$ rRNA is about $2 / 3$ of the mass of the $30 \mathrm{~S}$ particle. Ribosomal proteins are arranged around periphery of the subunit. The decoding region of 30S subunit, where synthesis of proteins takes place, is nearly free of proteins and the same holds true for the interface between $30 \mathrm{~S}$ and 50S subunits. Many of the crosslinks analyzed here for their wavelength dependence are located in or close to the cytoplasmic surface of the $30 \mathrm{~S}$ subunit, so it is not surprising that they may have a water environment. The two striking exceptions to this are crosslinks 967 x 1400 and 1402 x 1501. These are quite close to each other in the active site of $30 \mathrm{~S}$ particle. The results suggest unusual electronic environments in this particular part of the $30 \mathrm{~S}$ subunit.

Future Work. There are still many more experiments that can be performed to further characterize the influence of molecular environment at absorption spectra of nucleotides. To estimate the photoreversal of a crosslink, a band representing the crosslink can be excised from a preparative gel, the crosslinked molecules can be recovered from the gel with cesium chloride and then re-irradiated at the wavelength shorter then the absorption maximum for the crosslink (where, presumably, the dimers absorb more strongly then monomers). Upon this re-irradiation crosslinked molecules will convert to their initial state. When this sample is run again on the polyacrylamide gel the photoreversal would result in decrease or disappearance of the corresponding band on the gel. 
The same irradiation experiment described here for $30 \mathrm{~S}$ ribosomal subunits could be performed with $70 \mathrm{~S}$ ribosomes to determine if the action spectra of the crosslinks examined would change. The extension of those experiments is irradiation of 16S RNA in water. The crosslinks formed can be characterize in the same way as was described above and the comparison of their photoreactivity can be used to evaluate the impact of molecular environment on the absorption of that particular nucleotides. The same series of experiments could also be done in complexes of $30 \mathrm{~S}$ ribosomal subunits with different tRNAs and mRNAs. 


\section{REFERENCES}

1. Sinsheimer, R. L., and Hustings R. (1949) A reversible photochemical alteration of uracil and uridine. Science, 110, 525.

2. Wang, S. Y., (1976) in Photochemistry and photobioligy of nucleic acids. (Wang S. Y., Ed.), pp. 296-356, Vol. 1, Academic press, New York.

3. Gilbert, A., Baggott, J., (1991) in Essentials of Molecular Photochemistry, Blackwell Scientific Publications, Inc., Cambridge, MA.

4. Smith, K. C., (1967) in Radiation research, North-Holland Publ., Amsterdam.

5. Voet, D., Gratzer, W. B., Cox, R. A., Doty, P. (1963) Absorption spectra of nucleotides, polinucleotides and nucleic acids in the far ultraviolet. Biopolymers, 1, 193.

6. Greenstock, C. L., Brown, I. H., Hunt, J. W and Johns, H. E. (1967) Photodimerization of pyrimidine nucleic acid derivatives in aqueous solutions and the effect of oxygen. Biochem. Biophys. Res. Commun., 27, 431.

7. Beukers, R . and Berends, W. (1961) Effects of UV irradiation on nucleic acids and their components. Biochim. Biophys. Acta, 49, 181.

8. Sztumpf-Kulikowska, E., Shugar, D. and Boag, J. W. (1967) Kinetics of photodimerization of orotic acid in aqueous medium. Photochem. and Photobiol., 6, 41.

9. Herbert, M. A., LeBlanc, J. C., Weinblum, D., and Johns, H. E. (1969) Properties of thymine dimers. Photochem. and Photobiol., 9, 33.

10. Atmadjia, J., and Brimacombe, R. (1985) Investigation of the tertiary folding of Escherichia coli 16S RNA by in situ intra-RNA cross-linking within 30S ribosomal subunits. Nucleic Acids Res., 13, 6919-6937.

11. Atmadjia, J., Stiege, W., Zobava, M., Greur, B., Osswald, M. and Brimacombe, R. (1986) The tertiary folding of Escherichia coli 16S RNA, as studied by in situ intra-RNA cross- 
linking of 30S ribosomal subunits with bis-(2-chlorethyl)-methylamine. Nucleic Acids Res., 14, 659-673.

12. Doring, T., Greur, B., and Brimacombe, R. (1992) The topography of the 3'-terminal region of Escherichia coli 16S ribosomal RNA: an intra-RNA cross-linking study. Nucleic Acids Res., 20, 1593-1597.

13. Wilms, C., Noah, J. W., Zhong, D., and Wollenzien, P. (1997) Exact determination of UVinduced crosslinks in $16 \mathrm{~S}$ ribosomal RNA in 30S ribosomal subunits. RNA, 3, 602-612.

14. Noah, J. W., and Wollenzien, P. (1998) Dependence of the 16S rRNA decoding region structure on $\mathrm{Mg}^{2+}$, subunit association, and temperature. Biochemistry, 37, 15442-15448.

15. Kland, M. J., and Johnson, L. A. (1957) J. Amer. Chem. Soc., 79, 6187.

16. Kumar, S., Joshi, P.C., Sharma, N. D., Bose , S. N., Davies, R. J. H., Takeda, N., and McCloskey, J. A. (1991) Adenine photodimerization in deoxyadenylate sequences: elucidation of the mechanism through structural studies of a major $\mathrm{d}(\mathrm{ApA})$ photoproduct. Nucleic Acids Res., 19, 2841-2847.

17. Lebedeva, L. I., Ostrovskaia, R. M, Tsimmerman, V. G (1978) Possible role of protein in the development of UV-induced isochromatid breaks. Genetika, 14, 256-66. Article in Russian.

18. Matsunaga, T., Heida, K., and Nikaido, O. (1991) Wavelength dependent formation of thymine dimers and (6-4)photoproducts in DNA by monochromatic ultraviolet light ranging from 150 to 365 nm. Photochem. Photobiol., 54, 403-410.

19. Yamada, H., and Heida, K. (1992) Wavelength dependence (150 - $290 \mathrm{~nm})$ of the formation of the cyclobutane dimer and the (6-4) photoproduct of thymine. Photochem. Photobiol., 55, $541-548$.

20. Gurzadyan, G. G., and Gorner, H. (1993) Photolesions in DNA upon 193 nm excitation. Photochem. Photobiol., 58, 71-80.

21. Kochevar, I. E., and Buckley, L. A. (1990) Photochemistry of DNA using 193 nm excimer laser radiation. Photochem. Photobiol., 51, 527-532. 
22. Gut, I. G., Hefets, V., Kochevar, I. E., and Hillenkamp, F. (1993) Two-photon absorption cross sections of guanosine 5'- monophosphate and uridine 5'-monophosphate at $532 \mathrm{~nm} . J$. Phys. Chem., 97, 5171-5176.

23. Zweib, C., Ross, A., Rinke, J., Meinke, M, and Brimacombe, R. (1978) Evidence for RNARNA cross-link formation in Escherichia coli ribosomes. Nucleic Acids Res., 5, 2705-2719.

24. Zweib, C., and Brimacombe, R. (1980) Localization of a series of intra-RNA cross-links in 16S RNA, induced by ultraviolet irradiation of Escherichia coli 30S ribosomal subunits. Nucleic Acids Res., 8, 2397-2411.

25. Noah, J. W., Shapkina, T., and Wollenzien, P. (2000) UV-induced crosslinks in the $16 \mathrm{~S}$ rRNA of Escherichia coli, Bacillus subtilis and Thermus aquaticus and their implication for ribosome structure and photochemistry. Nucleic Acids Res., 28, 3785-3792.

26. Gilbert, A. and Baggott, J. (1991) in Essentials of Molecular Photochemistry. Blackwell Scientific, Cambridge, MA.

27. Makhno, V. I., Peshin, N. N., Semenkov, Y. P., Kirillov, S. V. (1988) Modified method of producing "tight" $70 \mathrm{~S}$ ribosomes from Escherichia coli, highly active in individual stages of the elongation cycle. Mol. Biol., 22, 528-537.

28. Webb, R. B., Lorenz, J. R. (1970) Oxygen dependence and repair of lethal sffects of near ultraviolet and visible light. Photochem. Photobiol., 12, 283-289.

29. Juzumiene, D., Shapkina, T., Kirillov, S., and Wollenzien, P. (2001) Short-range RNA-RNA crosslinking methods to determine rRNA structure and interactions. Methods, 25, 333-343.

30. England, T. E., Bruce, A. G., and Uhlenbeck, O. C. (1980) Specific labeling with T4 RNA ligase. Methods in Enzymology, 65, 1980.

31. England, T., and Uhlenbeck, O. (1978) 3'-terminal labeling with T4 RNA ligase. Nature, 275, $560-561$.

32. Krzyzosiak, W., Denman, R., Nurse, K., Hellmann, W., Boublik, M., Gehrke, C. W., Agris, P.F., and Ofengand, J. (1987) Biochemistry, 26, 2353-2364. 
33. Desgres, J., Gehrke, C. W., and Kuo, C. T. (1990) in Chromatography and modification of nucleosides. (Gehrke, C. W., and Kuo, C. T., Ed.), p. A216, Vol. 45A, ELSEVIE, Amsterdam - Oxford - New York - Tokyo. 